https://helda.helsinki.fi

\title{
Cognitive Science and the Double Vision of Fiction
}

\section{Polvinen, Merja Kristiina}

Oxford University Press USA

2017

Polvinen, M K 2017 , Cognitive Science and the Double Vision of Fiction . in M Burke \& E T Troscianko (eds), Cognitive Literary Science : Dialogues between Literature and Cognition .

Oxford University Press USA , New York , pp. 135-150 . https://doi.org/10.1093/acprof:oso/9780190496869.003.000

http://hdl.handle.net/10138/298557

https://doi.org/10.1093/acprof:oso/9780190496869.003.0008

unspecified

acceptedVersion

Downloaded from Helda, University of Helsinki institutional repository.

This is an electronic reprint of the original article.

This reprint may differ from the original in pagination and typographic detail.

Please cite the original version. 
Dr Merja Polvinen

Helsinki Collegium for Advanced Studies

University of Helsinki

\section{Cognitive Science and the Double Vision of Fiction}

Post-print version

Published in Cognitive Literary Science: Dialogues Between Literature and Cognition. Eds. Michael Burke and Emily T. Troscianko, Oxford University Press, USA, 2017.

\section{Introduction}

What is the difference between readers' experience of fictional and nonfictional narratives? How might the cognitive sciences be able to capture that difference? In order to work towards answers to these questions, this chapter focuses on the cognitive processes engaged in readers of fictional narratives. It brings together some recent literary theories of the imagination and fictionality, on the one hand, and views of perceptual experience presented within the enactive paradigm of cognitive science, on the other. What these approaches share is a view of the human imagination as a process that is both fundamental to our ability to negotiate our physical and social world, and complex and multi-layered enough to resist easy analysis. Fictionality studies and enactive cognition have also both presented valuable alternatives to some intuitive assumptions about the imagination, assumptions which have to a large extent been reproduced within the computational paradigm of cognitive science.

Within computationally inflected neuroscience, the imagination has mainly been discussed in the context of visual perception, memory and future projection (e.g. the production of mental imagery on the basis of recollected details, or the mental replication of actions through the mirror neuron system; Denis, 2001). While many of these earlier studies understood the imagination specifically as a process of forming mental images, today's research explores more widely the ways in which human beings imagine alternate realities - whether in everyday situations or as the audience of works of fiction. ${ }^{1}$ However, because the computational model of the mind follows centuries of tradition in assuming that human cognition is primarily rational, it presupposes that the fundamental operations of the imagination must also follow rules of logical information processing. While studies of the imagination in the humanities 
might be quick to deny such an assumption, the computational drive inherited by many cognitive studies of literature leads, I suggest, to the neglect of those effects of fictionality that depend on contradictions between what is known and what is experienced. Cognitive literary studies are thus at risk of pushing the imagination to fit within a model which erases many of the capacities that actually make it interesting to a humanities scholar. Alan Richardson (2011, 2015), from his position as specialist in the Romantic period, points out how little attention the mainstream cognitive discussion has paid to those humanities debates that emphasise the irrational, emotional and experiential aspects of the phenomenon. The imagination as conceptualised within the cognitive sciences is "strangely attenuated—one might even say tamed”, Richardson suggests, because the computational perspective of the scientists aims to "render the imagination rule bound and quotidian" (Richardson, 2011, p. 664-665; see also Danta \& Groth, 2014, p. 7).

But it should also be noted that the cognitive sciences, in moving away from the computational paradigm, are themselves becoming more interested in the wilder and weirder sides of the imagination, and in this chapter I would like to focus on the ways that the combination of the enactive paradigm within the cognitive sciences and the theories of fictionality within literary studies can help each other in forming a more nuanced view of the imagination for both fields of study.

\section{Fictionality in empirical studies of literature}

Taking up Richardson's call for more complex views of the imagination in cognitive literary studies, I argue that approaching fiction as fiction is a central element in literary imagining. The underlying idea is that readers of fiction engage in a seemingly contradictory interplay of the immersive and the reflective aspects of fiction. Such a view, while amply theorised within literary studies, has been largely absent from the empirical studies on readers' experiences of fiction. This is true, for example, of Green and Brock’s (2000, p. 704) much-referenced “Transportation Scale”, a questionnaire formulated for studying the depth of readers' immersion in a fictional world. ${ }^{2}$ The scale measures aspects such as imagery, involvement, emotional effects and distance from reality, and respondents are asked to rate these effects on a scale of 0-60. However, some items on the questionnaire reveal the scholars' assumption that involvement with narrative can only mean engagement with the 
events and characters represented, not engagement with the artefact itself. Thus, even though questions 4 ("I was mentally involved in the narrative while reading it") and 8 ("I found myself thinking of ways the narrative could have turned out differently”) can be answered positively when readers' involvement is with the level of storytelling rather than (or as well as) the events, the scale interprets all positive answers as counting towards the respondents being, in Green and Brock’s (2000, p. 701) terms, “'transported' into the world of the narrative and [becoming] involved with its protagonists". Another example comes from one of the most publicised recent experiments concerning the effects of literature, David Comer Kidd's and Emanuele Castano's 2013 article in Science. Their results seem to show that literary fiction improves our understanding of other minds more than do either nonfiction or popular fiction. The argument is based on the statistical analysis of readers' self-reports in five separate experiments, of which the first includes the fiction/nonfiction condition. In that study, however, the comparison is undermined by the fact that the authors deliberately chose nonfiction texts that "primarily focused on a nonhuman subject", while the fictional texts included “at least two characters” (Kidd \& Castano, 2013, supplementary material), as if the difference between the two modes consisted simply in the presence or absence of people to empathise with. With such a choice of material, the more active priming of interpersonal skills in readers of the fiction texts can hardly be a surprise, and the findings, such as they are, speak only to the effects of characterisation, not those of fiction or nonfiction.

These studies, like most empirical work on fictionality, used self-report questionnaires. One of the few neurophysiological studies of the difference between fiction and nonfiction was conducted by Altmann et al. (2014) to examine how paratextual information shapes the reading process. Participants read dozens of c. 50word narratives arbitrarily labelled as either fiction or nonfiction, while their brains were scanned using fMRI. The main findings here indicate that the texts flagged as nonfiction engaged systems associated with the simulation physical actions, whereas with texts flagged as fictions the activation patterns were more like those associated with “mind-wandering” and "relational inferences” (Altmann et al., 2014, p. 26). Such results, creating a tenuous connection between fiction-reading and the openminded readiness of hypothetical thinking, are attractive (see also Richardson, 2011, pp. 685-687), and indicate that it is worthwhile to pay attention to relational as well as action-related cognition in the processing of narratives. However, since Altmann 
and colleagues wanted to focus primarily on the intersubjective aspects of reading, the participants were also asked to fill out the Interpersonal Reactivity Index (IRI) devised by Mark H. Davis (1980). These results were then compared with the strengths of the activation patterns indicating mentalising - the act of imagining other minds. Altmann and colleagues are careful as to the extent of the conclusions they draw from these results, but the suggestion is that because brain patterns indicating mentalising are more strongly activated in individuals who self-report a strong identification with fictional characters in general, and because the same patterns of activation are more strongly manifest in reading fiction than nonfiction, fiction can be said to differ from nonfiction because it engages our interpersonal cognition more fully.

While the fMRI results themselves are intriguing, I would like to draw attention to one detail in this study that is arguably problematic from the point of view of the literary view of the imagination. Altmann et al. (2014, p. 24) base the correlation between the fMRI results and the respondents' general tendency to engage with characters on one of the four factors identified in the IRI- the "Fantasy Scale" (Davis 1980, table 3). This section focuses on reactions to fictional characters, and even though is designed for the measurement of empathetic skill rather than the reading of fiction more generally, in it empathetic identification is itself conceptualised in roughly similar ways as immersion or transport in literary studies, and equated with successful engagement with fiction. Thus, some Fantasy Scale items adopt the common shorthand of assuming that 'good' or 'interesting' stories or films are by definition those that promote an empathic identification, and positive answers to questions like "When I am reading an interesting story or novel, I imagine how I would feel if the events of the story were happening to me" (item 26) and "When I watch a good movie, I can very easily put myself in the place of a leading character" (item 23), are seen to indicate high tendency to empathise. However, also responses indicating whether or not participants tend to get "caught up in" or "involved in" a story (items 7 and 12) are judged the same way, revealing an underlying assumption that such generally engaged reactions to fictions also designate empathy towards fictional characters. Since no option is given for respondents to indicate that they may be caught up in a novel's way of using language, in the intricacies of its narrative structures, or, indeed, in its fictionality, all responses to these questions end up counting towards an individual respondent's tendency to empathise. Furthermore, 
since the Fantasy Scale of the IRI does not correlate particularly strongly with the other three parts of this empathy measurement (Davis 1980, p. 14-15), the baseline against which Altmann and colleagues are measuring their participants' fMRI scans is arguably problematic.

What I suggest, therefore, is that we look critically at results from studies which start with the assumption that engagement with fiction functions only through empathic identification with fictional characters, or that such engagement requires a form of illusion or loss of a sense of the fictionality of the story. In the following I will argue that fiction is perceived through a double vision that is unlike the kind of “aesthetic illusion” (Wolf, 2013) that sets such awareness and engagement to work against each other.

\section{Enactive perception of fictions}

Despite the fact that many psychological and neurological studies of fictionality have suffered from the conceptual problems described above, the cognitive sciences can offer literary scholars valuable insights into how our general cognitive skills are activated not only by the environments or people represented in a text, but also by the fact of their fictionality. These insights are offered by the critique of the computational model that has appeared in the form of the ' $4 \mathrm{E}$ ' paradigm. This paradigm takes the mind to be embodied, embedded, enactive and extended (Menary, 2009; Stewart, Gapenne \& Di Paolo, 2010), and it presents a view of cognition that changes from a computer-like input-processing-output model to a system incorporating more complex_and more intractable—feedback between an embodied being and a dynamic environment. As such, the 4E approaches draw not only on neuropsychology but also on phenomenology—a combination that the computational paradigm has resisted (see e.g. Gallagher \& Zahavi, 2007; Noë, 2004, 2012; Thompson 2007).

My focus is on the consequences of enaction and embodiment for the imagining that readers undertake in experiencing fiction. Enactive cognition broadly takes thought to be "the exercise of skillful know-how in situated and embodied action”, in the sense that all our thinking-however abstract and introspective-is in constant feedback with "recurrent sensorimotor patterns of perception and action” (Thompson, 2007, p. 13). Consequently, an enactive understanding of literary reading 
conceives it also as a skill-orientated interaction between a reader's embodied mind and the literary object. Enactive cognition has already been shown to affect our understanding of fictionality in interesting ways, and new scholarship has presented analyses of embodied reactions to texts, including topics such as sensing fictional spaces (Caracciolo, 2011), experiencing movement and body boundaries (Esrock, 2001; Kuzmičová, 2012), or identifying embodied feelings coded into the rhythms of narrative (Caracciolo, 2014). For example, in her examination of perceptual experiences of narrative, Emily Troscianko (2013) emphasises the difference between the enactive view of imagining and the "picture in the head" variety presented in older forms of cognitive neuropsychology: “I don’t have a mental image of the cat I'm imagining”, she writes, "but I perform the same kinds of exploratory behaviours as when I see one, with weaker forms of sensory feedback provided from memory” (Troscianko, 2013, p. 185). What is crucial in such literary scholarship is its interaction with the enactive paradigm to produce a view of the literary imagination as a set of complex processes that engage the mind-body with the fictional environment offered by the text.

Troscianko (2013) has also drawn attention to the way in which our folkpsychological assumptions about the imagination often lump together several experiential aspects. Her example is the way in which the concept of 'vividness', much used in questionnaire studies of literary imagination, actually conflates two aspects: actual visual detail and emotional intensity. The unacknowledged presence of this conceptual amalgam, Troscianko argues, results in flawed experimental data about the exact processes involved. In a similar fashion, I wish to unpack another conceptual conflation: that what is being encountered during reading is in some senses like a world, but is a fiction. I am particularly interested in the role of the clearly signalled fictionality of the literary work in the process, and in how readers' minds are able to assume a perspective that is simultaneously aware of the fictionality of the events it follows and yet fully cognitively and emotionally engaged with them.

For the purpose of unpicking this conflation, I draw on the theory of enactive perception as presented in Alva Noë's Action in Perception (2004) and Varieties of Presence (2012). Perception, Noë argues, “is constituted not only by the perceiver's mastery of patterns of sensorimotor dependence, but by the fact that the perceiver knows that his or her relation to the environment is mediated by such knowledge" (Noë, 2004, p. 65). According to this "full-blooded duality of perceptual experience”, 
seeing, for example, a silver dollar from an angle includes an experience of the elliptical shape presented from that angle as well as the circularity we know the object to have, since our learned patterns of sensorimotor perception tell us that from an angle a circular object presents itself to us as elliptical (Noë, 2012, p. 52). Such experience includes not only how an object looks, but also how it is-two aspects of experience that arise from our knowledge of how objects look from various spatial positions we can have in relation to them. ${ }^{3}$ I suggest that the fictionality of a narrative could be seen as an analogy of our angled stance towards the silver dollar. The representation, by drawing on readers' everyday cognitive patterns, creates a sense of the verisimilitude of the storyworld, while at the same time that effect is itself dependent on readers' ability to negotiate narrative's fictional mode of representation. In some sense, then, in perceiving fictions we perceive them as both elliptical (verisimilar) and circular (fictional). It should be noted that for Noë the "full-blooded duality" of perception implies that experiencing how things are and how they seem is possible without shifting attention. Consequently, the view of the perception of fiction presented here differs from the plot-oriented prediction and hesitation effects examined by Karin Kukkonen in her contribution to this volume, in that fictionality and the fictional world are not like Wittgenstein's duck-rabbit—-two aspects impossible to see at the same time-but instead like seeing either one because we see the lines of the famous drawing. That is, we see the lines as either a duck or a rabbit, but in both cases we see both the lines and the animal (see Noë, 2012, p. 21-22 and Polvinen, forthcoming).

The full ramifications of this analogy should not be seen only in the context of specifically visual imagining, nor is this conceptualisation likely to support clear-cut ontological categories of fiction and nonfiction into which narratives could be divided (see also Polvinen, forthcoming). If applied to the entirety of our complex engagements with fictions, a theory of enactive perception of fictions as fictions demands much more work in terms of teasing out the various emphases in different texts. For this kind of work we can draw on literary scholarship which relies on ideas of praxis recognisable to those working within the enactive paradigm. For example, Joshua Landy's volume How to Do Things with Fictions (2012) combines literary analysis, hermeneutics and the philosophy of narrative fiction, and argues that one of the major functions of fictionality is to train the mind in assuming particular mental states. "Rather than providing knowledge per se," Landy writes, "whether 
propositional knowledge, sensory knowledge, knowledge by acquaintance, or knowledge by revelation — what [fictions can] give is know-how; rather than transmitting beliefs, what they equip us with are skills; rather than teaching, what they do is train. They are not informative, that is, but formative” (Landy, 2012, p. 10). Of particular interest is the way Landy bases the power of these "formative" fictions on the fact that in order to do the training they do, they must generate in their readers a state of "conviction and distrust" in the enchantment being offered (Landy, 2012, p. 76). In his analyses of texts that range from the Gospel of Mark to Mallarmé and Beckett, Landy thus lays open a form of writing that connects with its readers most acutely on a level of "lucid self-delusion” (Landy, 2012, p. 12). The combination of engagement with what seems to be the case, and awareness of the fact that we are being presented with an illusion, is a seemingly paradoxical mental state that is nevertheless required of us when experiencing such fictions. At the same time, the fictions themselves hone our skill in entering that state to an enduring and easy habit (see also Landy, 2015, p. 572).

Landy’s “lucid self-delusion” follows a tradition running from Aristotle’s mimesis (see Halliwell, 2002) to Coleridge's willing suspension of disbelief-of seeing fiction as something that calls not for a loss of a sense of reality, but for the maintenance of a dual attitude. ${ }^{4}$ It might be argued that these two aspects of engagement with fiction should be seen as distinct processes, one a low-level and intuitive perceptual process, the other a conscious and culturally organised process of interpretation (see e.g. Hutto \& Myin, 2013, p. xviii). However, it is crucial to this view of fictionality to recognise that perceptual and interpretive processes are always intertwined in reading, and that there are qualities in fictions which are available to the audience only when they use specific fiction-related cognitive skills. Such is the argument made by Richard Walsh in Rhetoric of Fictionality (2007), where fictionality is presented as a communicative strategy built into works of fiction by authors, and recognised as such by readers. Fictionality is therefore a rhetorical mode that changes the way readers comprehend the thing being represented: "awareness of its artifice is innate in any response whatsoever to fiction as such” (Walsh, 2007, p. 172). Thus losing sight of fictionality as a quality of the text would mean readers are no longer experiencing fiction but have, instead, slipped into a nonfictional mode of reading. 
By combining these 4E cognitive and literary-theoretical perspectives, I suggest, we can understand the experience of fiction as a form of enactive perception where fictionality, instead of being a quality that fades to invisibility in order to be effective, is rather the perspective that makes perception and comprehension of fiction as fiction possible. Furthermore, our experience of fictionality need not to clash with our perception of and engagement with the fictional world, but is conjoined with it. The enactive actualising of the cognitive process presented by a fictional narrative should not be understood only as a re-enactment of a character's experience (as the verisimilar content of the fictional representation), but must instead be seen to also involve the discourse patterning of the narrative-everything from individual linguistic details to its communicative status as a work of fiction.

\section{Fictionality and the products of magic: The Prestige}

In the space remaining, I will extend this theoretical discussion to the analysis of a novel which I believe cashes in on those imaginative processes which the enactive approach to fictionality brings to light. Christopher Priest's The Prestige (1995) is a meditation on the $19^{\text {th }}$ century and its tensions between spiritual and materialist sensibilities. This is a cultural moment that many other writers have approached through the spiritualist séances popular at the time (e.g. A.S. Byatt in her 1990 novel Possession), but Priest chooses as his entry point a feud between two stage magicians. In the novel, this conflict draws on two conceptualisations of magic, either as naturalised craft or as actual supernatural power, and the novel itself is similarly built on a conflict between naturalised narrative puzzles and fantastical story events. As a result, The Prestige has resisted easy categorisations, and has been cited as science fiction or fantasy, and as Neo-Victorian metafiction, having won both the mainstream James Tait Black Memorial Prize and the World Fantasy Award.

The novel opens in the present day with a young journalist receiving a copy of the diary of his Victorian ancestor, Alfred Borden. ${ }^{5}$ Borden was a hard-working tradesman's son who taught himself conjuring tricks and eventually made his way to the stage under the name "Le Professeur de Magie". In addition to the story of Borden's life, the diary includes sections where he explains his own attitude towards the secrets of his art. "Magic has no mystery to magicians," Borden believes. "We work variations of standard methods. ... Every illusion can be explained, be it by the 
use of a concealed compartment, by an adroitly placed mirror, by an assistant planted in the audience to act as 'volunteer', or by simple misdirection of the audience's attention” (Priest 1995/2004, p. 66). Borden’s most famous stage trick is exactly such a naturalisable mystery: in “The Transported Man” he steps into a cupboard on one side of the stage, seems to cross the entire width of that space instantaneously and step out of another cupboard on the opposite side. The pleasure and thrill of the trick, as Borden emphasises in his writings, is in that everyone knows that no magic is actually involved, and instead the mystery is created by skilled misdirection. The preservation of the mystery itself, however, is crucial, and the extent to which Borden is willing to go to maintain it goes to insane lengths. For what the diary slowly reveals is that "The Transported Man" is made possible by the fact that Borden is actually a pair of twins who, in order to protect the secret of their trick, take turns to live the life of a single individual—sharing their wife and children, as well as their mistress, and never letting on that they are, in fact, not one man but two.

Misdirection is also present in the form of Priest's novel, as the diary performs its own narrative trick on readers. Written entirely in the first-person singular-even though the two brothers take turns narrating their story - the diary simultaneously presents and conceals the solution to its own mystery:

I write in the year 1901.

My name, my real name, is Alfred Borden. The story of my life is the story of the secrets by which I have lived my life. ... .

First let me in a manner of speaking show you my hands, palms forward, fingers splayed, and I will say to you (and mark this well): "Every word in this notebook that describes my life and work is true, honestly meant and accurate in detail.” (Priest, 1995/2004, pp. 31-34)

Just like the audience of stage magic, the readers of Priest's novel receive this announcement of honesty from Borden, and both audiences acquiesce to experiencing the mystery that follows. Even the very first word of the diary, "I", is simultaneously a truth and a lie, one that readers are designed to accept at face value at first, but whose duplicity is made explicit later on. Borden's secret remains a secret to his stage audiences, but in the diary it is eventually naturalised by the revelation of the twins' unorthodox life and life-writing. This process takes up most of the first half of the book, making it read like a realist historical novel, with the twist of a psychological thriller. 
This effect, however, is offset by the fate of Priest's second diary-writing magician, Rupert Angier. Angier is in some ways Borden's opposite-the younger son of an Earl, he is wealthy and educated—but he does share Borden's obsessive drive to succeed as a magician. The fates of the two men are entangled by an accident that sets them in a spiral of competition and revenge, sabotaging each other's performances with tragic consequences. Against Borden’s methodical "Professeur”, Angier is the showman-enamoured with the magic act as spectacle. He finds Borden's performances to be impossibly skilful, yet banal in their use of "standard stage trickery”. But after trying and failing to produce the uncanny effect of Borden's “Transported Man” by engaging a stage double, Angier decides to match the same level of illusion by producing the truly impossible. He obtains from Nicola Tesla an electrical machine which transports him from the stage to the back of the theatre instantaneously. The trick is a huge success and it establishes Angier's career as one of the greatest magicians of his age. But because his audience expects to be engaging with an act of conjuring rather than with reality, Angier now needs to hide an actual scientific sensation: that although his trick "by scientific method, in fact achieves the hitherto impossible", he "cannot allow this ever to be known, for science has in this case replaced magic” (Priest, 1995/2004, p. 282). Even though the truth of his trick is a scientific miracle, Angier strives to maintain the traditional, 'magical' audience relation. "By careful art”, he has to "make [his] miracle less miraculous” in order to have it accepted as magic.

Tesla's machine is, of course, an impossiblity in our reality, and its presence transforms the historical realism of Priest's novel into science fiction or steampunk. It also ushers in the Gothic and the grotesque. For, strictly speaking, Tesla's machine does not transport anyone anywhere; instead it places a living copy of the person at any location chosen. The Angier who steps into the machine is thus copied every night he performs the trick, and the inert but living original is each time secreted away from the theatre and placed in Angier's family vault. This goes on until the night Borden interferes with the trick, resulting in the "original” Angier remaining mobile (though weak) and the new copy gaining only a ghostlike existence. Angier, like Borden, becomes two halves of a single man, but in this case neither half is physically viable. The original Angier is eventually riddled by cancer and dies, while the copy remains mostly insubstantial. 
Angier's diary knowingly repeats Borden's diary illusion, as both the original but physically damaged version and the final surviving but incorporeal version of Angier use the first-person singular in writing it. The switch between the two occurs initially without express signal, but the narrative situation of the diary eventually alerts readers by becoming seemingly impossible, with Angier describing his own unconsciousness and paralysis and finally even his own death: "At a quarter to three this morning my life was brought to its end by a sudden seizure of the heart” (Priest, 1995/2004, p. 323-325). But unlike Borden's diary, this time the narrative has dropped enough hints about the doubling to make it reasonably easy for readers to understand that Angier is writing about the death of his other half. And even those readers who are caught by this first-person-for-two-men trick for the second time are quickly let off the hook by Angier making explicit reference to Borden’s doubled voice: "I have borrowed a technique from Borden, so that I am I as well as myself" (Priest, 1995/2004, p. 325).

Yet, despite the fact that Angier's narrative situation is naturalised to an extent-he turns out not to be an undead man speaking from beyond the grave- the fact of his doubling into corporeal and incorporeal versions is itself a deviation from the rules of our reality. Thus with Angier, we are no longer able to explain the doubled man as a psychologically twisted but ultimately possible set of twins, and Priest no longer continues to operate within the naturalist or realist literary tradition. The genre of science fiction has been for a long time theorised mainly through its presentation of scientifically believable speculation (e.g. Spiegel, 2008)—an approach which relies on the assumption that invented technology inherently offers more cognitive grounding than the supernatural phenomena typical to fantasy. In The Prestige, Priest clearly plays with that assumption by having Angier's impossible magic act be made plausible by a machine invented by a historical person. But even the science-fictional naturalisation is only the first step in the process dominating Angier's story. During his career, he was able to fool his theatre audiences into continuing to take the fictional attitude towards his performances, but the full, grotesque consequences of actual impossibility are represented to the reading audience. These are manifested, firstly, by the description of the frame-tale narrator's final descent into the crypt among dozens of immobile but still conscious, rubbery Angier copies - undead interstitial beings (see Csicsery-Ronay, 2008, p. 195-198) that are all the more horrifying for appearing in a series of absurd poses: 
The corpses all lay in different positions. Some were straight, others were twisted or bent over. None of the bodies was arranged as if lying down; most of them had one foot placed in front of the other, so that in being laid on the rack this leg was now raised above the other.

Every corpse had one foot in the air. ...

I eased myself backwards, not looking. As I reached the main aisle and turned slowly around, [I] brushed against the raised foot of the nearest corpse. A patent-leather shoe swung slowly to and fro. (Priest, 1995/2004, pp. 354357)

Furthermore, intertextual allusions at the end of the novel usher in the ghosts of both Mary Shelley’s Frankenstein and Robert Luis Stevenson's Dr. Jekyll and Mr. Hyde, as the final phantom-Angier, re-embodied in one of his own earlier copies, disappears off into a blizzard. Thus this novel presents its readers with multiple perspectives to the phenomenon of magic —as stage performance, as supernatural power, and as fiction.

The motivation for using stage magic as an analogy for fiction in this chapter — and, I believe, in Priest's novel—is to emphasise the roles of the two aspects of fictionality I wanted to focus on: the audience's expectation of unreality and their engagement with the entire act of conjuring, rather than just with the world or the actions it seems to represent. It is through the contrast between the two magicians and their attitudes, as well as the genre conventions of realism and the fantastic adopted in the novel, that Priest expressly signals to his readers the kind of enaction they are engaged in. That signalling gesture, like the empty hands of the magician, is designed to remind readers to engage with the fiction as fiction, with "a verbal performance in which the events depicted never happened, and in which everyone knows they didn't” (Landy, 2012, p. 3). But the central purpose of underlining this role of artificiality in fiction is not to undermine the readers' enactment — on the contrary. For even while we are enacting the experiences represented in the fiction, what is also being enacted is the work of fiction itself. And what follows from that enaction is not what would follow from engagement with reality-a point underlined by the title of Priest's novel. "The prestige" refers, in the vocabulary of stage magic, to the "effect" or the "product of magic", to that which "apparently did not exist before the trick was performed” (Priest, 1995/2004, p. 65). Angier's trick produces copies of himself, whereas Borden talks about his whole, bizarre life as the prestige of “The Transported Man” (Priest, 1995/2004, p. 65). But fiction, I suggest, can also produce in readers its own prestige, something that emerges as if by magic from the process of readerly enactment. The 
prestige of fiction is not a rabbit pulled out of a hat, nor something as grotesque as Angiers' copied bodies; it is a cognitive state of lucid self-delusion in readers, which would not be without having been performed through active complicity in a fiction as fiction, and with full knowledge of the meaning-making actions required in that performance.

\section{Conclusion}

Fictions are interactive cognitive environments that require from readers a combination of skills that is much more complex and seemingly self-contradictory than the traditional computational cognitive sciences assume. In recent years, however, it has become clear also within the cognitive sciences that the use of residual common-sense concepts may lead scholars into making oversimplifying claims. As Howard Casey Cromwell and Jaak Panksepp (2011) have noted, the cognitive and behavioural neurosciences sometimes do fall prey to a form of circularity in their attempts to accurately describe the workings of the human brain. Citing the NYU neuroscientist Gyorgy Buzsaki they note how the conceptual structures created through slow processes of tradition can lead empirical research to merely reproduce those structures, to take "a man-created word or concept ... and search for brain mechanisms that may be responsible for the generation of this conceived behaviour” (Cromwell \& Panksepp, 2011, 2034). In a similar fashion, the risk I see in some of the recent cognitive and empirical studies of fiction is that they uncritically adopt apparently universal, common-sense concepts that have received added legitimacy from the rational/computational tradition. Such studies may end up just confirming the preconceptions of the researchers because of the way the conceptualisations guide the set-up of the experiments, in for example the verbal instructions or choices provided in questionnaires, or even because they limit the vocabulary available for the participants to describe their experiences (see Troscianko, 2013, p. 190-191).

My aim here has therefore been to show how, by focusing on fictionality, cognitive literary studies would be better able to analyse those functions and effects that arise from the artefactual nature of the text, instead of focusing on just the effects that are thought to exist in spite of that artefactuality. Secondly I have tried to suggest that the cognitive sciences might benefit from the ideas and analyses presented by literary studies concerning the complexities involved in the processing of fictional 
narratives, and the ways in which that processing is unlike the forms of immersive illusion often used as the paradigm cases of literary imaging. While there is already much intriguing data relating to our imaginary abilities coming from the empirical neurosciences, the results of such studies will be difficult to interpret as long as the underlying conceptualisations are still rooted in oversimplifying models. By combining the theory of fictionality and the enactive paradigm of perception and imagination, the cognitive sciences might be able to further sharpen their own conceptual and terminological apparatus and continue to generate fruitful hermeneutic circulation between different approaches to the mind and the imagination.

\section{Notes}

1. Other terms in use when discussing the imagination include "make-believe" (e.g. Walton, 1990), which is in use in developmental psychology and the anthropology of play, and "simulation", which is seen by many cognitive scientists as an integral part of social cognition (e.g. Gallese, Keysers \& Rizzolatti, 2004).

2. The Transportation Scale is cited e.g. by Appel \& Richter (2007), Bae, Lee \& Bae (2014), Phillips (2015) and Sanford \& Emmott (2012).

3. For a challenge of Noë's argument concerning sensorimotor knowledge see e.g. Hutto \& Myin (2013), who argue for a more radical version of contentless cognition.

4. Further work in this tradition includes Wolfgang Iser's The Fictive and the Imaginary (1993) and Paul Ricoeur's three-level mimesis in Time and Narrative (1984-1988).

5. For an analysis of Christopher Nolan's film version from 2006, where some substantial changes were made to the way the battle between the magicians is presented to the audience, see Heilmann (2009/2010). The modern-day frame of the novel is honestly less interesting than the Victorian magicians, and it was left out of Nolan's film.

\section{Works Cited}

Altmann, U., Bohrn, I. C., Lubrich, O., Menninghaus, W. \& Jacobs, A. M. (2014). Fact vs fiction: How paratextual information shapes our reading processes. Social Cognitive and Affective Neuroscience 9, 22-29. doi:10.1093/scan/nss098

Appel, M. \& Richter T. (2007). Persuasive effects of fictional narratives over time. Media Psychology 10, 113-134. doi: 10.108/15213260701301194

Bae, H.-S., Lee, D. \& Bae, R.E.G. (2014). Emotional engagement with the plot 
and characters: A narrative film on hearing-impaired sexual assault victims. Narrative Inquiry 24(2), 309-327.

Caracciolo, M. (2011). The reader’s virtual body: Narrative space and its reconstruction. Storyworlds 3, 117-138.

Caracciolo, M. (2014). Tell-tale rhythms: Embodiment and narrative discourse. Storyworlds 6(2), 49-73.

Cromwell, H. C. \& Panksepp, J. (2011). Rethinking the cognitive revolution from a neural perspective. Neuroscience and Biobehavioral Reviews 35, 2026-2035.

Csicsery-Ronay Jr., I. (2008). The seven beauties of science fiction. Middletown, CT: Wesleyan University Press.

Danta, C. \& Groth, H. (2014). Introduction: Between minds. In Mindful aesthetics: Literature and the science of mind (pp. 1-14). New York et al.: Bloomsbury.

Davis, M. H. (1980). A multidimensional approach to individual differences in empathy. JSAS Catalog of Selected Documents in Psychology 10, 85. http://www.eckerd.edu/academics/psychology/files/Davis_1980.pdf

Denis, M. (2001). Mental Imagery, Psychology of. International Encyclopedia of the Social and Behavioral Sciences (pp. 9675-9681).

Esrock, E. J. (2001). Touching art: Intimacy, embodiment, and the somatosensory system. Consciousness and Emotion 2(2), 233-253.

Gallagher S. \& Zahavi D. (2007). The Phenomenological Mind. London: Routlege.

Gallese, V., Keysers C. \& Rizzolatti G. (2004). A unifying view of the basis of social cognition. Trends in Cognitive Sciences 8(9) 396-403.

Green, M. C., \& Brock, T. C. (2000). The role of transportation in the persuasiveness of public narratives. Journal of Personality and Social Psychology 79(5), 701-721. doi:10.1037//0022-3514.79.5.701

Halliwell, S. (2002). The aesthetics of mimesis: Ancient texts and modern problems. Princeton and Oxford: Princeton University Press.

Heilmann, A. (2009/2010). Doing it with mirrors: Neo-Victorian metatextual magic in Affinity, The Prestige and The Illusionist. Neo-Victorian Studies 2(2), 18-42.

Hutto, D. D. \& Myin E. (2013). Radicalizing enactivism: Basic minds without content. Cambridge, MA: MIT Press.

Iser, W. (1993). The fictive and the imaginary: Charting literary anthropology. Baltimore and London: Johns Hopkins University Press. 
Kidd, D. C. \& Castano, E. (2013). Reading literary fiction improves Theory of Mind. Science 342(18 October), 377-380, with online supplementary material. doi:

10.1126/science.1239918

Kuzmičová, A. (2012). Presence in the reading of literary narrative: A case for motor enactment. Semiotica 189(1), 23-48. doi: 10.1515/semi.2011.071

Landy, J. (2012). How to do things with fictions. Oxford and New York: Oxford University Press.

Landy, J. (2015). Mental calisthenics and self-reflexive fiction. In L. Zunshine (Ed.), Oxford handbook of cognitive literary theory, (pp. 559-580). Oxford et al.: Oxford University Press.

Menary, R. (2009). Introduction to the special issue on 4E cognition. Phenomenology and the Cognitive Sciences 9, 459-463. doi: 10.1007/s11097-010-9187-6

Noë, A. (2004). Action in perception. Cambridge, MA: MIT Press.

Noë, A. (2012). Varieties of presence. Cambridge, MA and London: Harvard University Press.

Phillips, N.M. (2015). Literary neuroscience and history of mind: An interdisciplinary fMRI study of attention and Jane Austen. In L. Zunshine (Ed.), Oxford handbook of cognitive literary theory, (pp. 55-81). Oxford et al.: Oxford University Press.

Polvinen, M. (forthcoming). Enactive perception and fictional worlds. In P. Garratt (Ed.), The cognitive humanities: Embodied mind in literature and culture. London: Palgrave.

Priest, C. (2004). The Prestige. London: Gollanz. (Originally published 1995)

Richardson, A. (2011). Defaulting to fiction: Neuroscience rediscovers the Romantic imagination. Poetics Today 32(4), 663-692. doi: 10.1215/03335372-1459845

Richardson, A. (2015). Imagination: Literary and cognitive intersections. In L. Zunshine (Ed.), Oxford handbook of cognitive literary theory, (pp. 225-245). Oxford et al.: Oxford University Press.

Ricoeur, Paul. 1984-1988. Time and Narrative Vols. 1-3. (K. McLaughlin and D. Pellauer, Trans). Chicago and London: University of Chicago Press. (Original work published 1983-1985)

Sanford, A. J. \& Emmott, C. (2012). Mind, brain and narrative. Cambridge et al.: Cambridge University Press.

Spiegel, S. (2008). Things made strange: On the concept of "estrangement” in science fiction theory. Science Fiction Studies 35(3), 369-385. 
Stewart, J., Gapenne, O. \& Di Paolo, E. A. (2010). Introduction. In Enaction: Toward a new paradigm for cognitive science (pp. vii-Xvii). Cambridge, MA: MIT Press.

Thompson, E. 2007. Mind in Life: Biology, Phenomenology, and the Sciences of Mind. Cambridge, MA and London: Belknap.

Troscianko, E. T. (2013). Reading imaginatively: The imagination in cognitive science and cognitive literary studies. Journal of Literary Semantics 42(2), 181-198.

Walsh, R. (2007). The rhetoric of fictionality. Columbus, OH: Ohio State University Press.

Walton, K. L. (1990). Mimesis as make-believe: On the foundations of the representational arts. Cambridge, MA: Harvard University Press.

Wolf, W. (2013). "Unnatural” metalepsis and immersion: Necessarily incompatible? In J, Alber, H. S. Nielsen \& B. Richardson (Eds.), A poetics of unnatural narrative (pp. 113-141). Theory and Interpretation of Narrative. Columbus: Ohio State University Press. 